\title{
O ENSINO DE CIÊNCIAS: ESPECIFICIDADES PEDAGÓGICAS ENTRE O DIZER E O FAZER
}

\section{SCIENCE TEACHING: PEDAGOGICAL SPECIFICITIES BETWEEN SAYING AND DOING}

Débora Luana Kurz ${ }^{1}$

ORCID iD: 0000-0002-8790-5376

Everton Bedin ${ }^{2}$

ORCID iD: $\underline{0000-0002-5636-0908}$

Claudia Lisete Oliveira Groenwald ${ }^{3}$

ORCID iD: $\underline{0000-0001-7345-8205}$

\section{RESUMO}

Considerando as especificidades e as implicações das narrativas de três professoras, bem como as particularidades da ação pedagógica destas à luz do contexto escolar, no intuito de averiguar indícios da área das Ciências da Natureza em meio à prática pedagógica, buscou-se analisar, refletir e discutir sobre as possibilidades desencadeadas por estas para o acesso à cultura científica aos alunos desde o início do processo de escolarização. Os dados foram coletados por meio da observação e posterior transcrição em um diário de bordo, além da aplicação de um questionário analisado no viés qualitativo da pesquisa fenomenológico-hermenêutica. Nesse sentido, pontua-se que apesar de haver um consenso em relação a importância do ensino de Ciências da Natureza no início do processo de escolarização, evidencia-se limitados indícios de Ciências tanto na narrativa das professoras quanto durante o período de observação das aulas. É necessário que esta discussão permeie os processos de formação de professores, e que a mesma seja contemplada de forma articulada à BNCC.

Palavras-chave: Ciências da Natureza. Anos iniciais do Ensino Fundamental. Formação Docente.

\begin{abstract}
Considering the specificities and the implications of the narratives of three teachers, as well as the particularities of their pedagogical action in the light of the school context, in order to investigate evidence from the area of Natural Sciences in the midst of pedagogical practice, we sought to analyze, to reflect and to discuss the possibilities triggered by them for access to scientific culture to students since the beginning of the schooling process. Data were collected by observation and subsequent transcription in a logbook, beyond the application of a questionnaire analyzed in the qualitative bias of phenomenological-hermeneutic research. In this sense, it is pointed out that although there is a consensus regarding the importance of teaching Natural Sciences at the beginning of the schooling process, there

\footnotetext{
${ }^{1}$ Mestranda do Programa de Pós-Graduação em Ensino de Ciências e Matemática da Universidade Luterana do Brasil (ULBRA), Canoas/RS, Brasil. Endereço para correspondência: Av. Farroupilha, nº 8001 - São José, Canoas, Rio Grande do Sul, Brasil, CEP: 92425-020. kurz.deboraluana@ gmail.com.

${ }^{2}$ Doutor em Educação em Ciências pela Universidade Federal do Rio Grande do Sul (UFRGS), Porto Alegre/RS, Brasil. Professor da Universidade Federal do Paraná (UFPR). Endereço para correspondência: Jardim das Américas, Curitiba, Paraná, Brasil, CEP: 81531-980. everton.bedin@gmail.com.

${ }_{3}$ Doutora em Ciências da Educação pela Pontifícia de Salamanca na Espanha. Professora da Universidade Luterana do Brasil (ULBRA), Canoas/RS, Brasil. Endereço para correspondência: Av. Farroupilha, $n^{\circ} 8001$ - São José, Canoas, Rio Grande do Sul, Brasil, CEP: 92425-020. claudiag@ulbra.br.
} 
is limited evidence of science both in the teachers' narrative and during the observation period of the classes. Is necessary that this discussion permeates the processes of initial and continuing teacher education, and that it be contemplated in an articulated manner to the BNCC

Keywords: Natural Sciences. Early years of elementary school. Teacher Education.

\section{INTRODUÇÃO}

O ensino de Ciências da Natureza, de acordo com Lorenzetti e Delizoicov (2001), tem o compromisso de propiciar ao aluno o acesso ao conhecimento científico, visando-lhe o desenvolvimento cognitivo para que seja capaz de compreender as especificidades à sua volta, posicionando-se e intervindo frente a realidade a que se insere. Corroborando, Kurz e Bedin (2019, p. 247) contemplam que esta área visa "promover a aprendizagem dos conhecimentos científicos, os quais corroboram para a compreensão dos fenômenos presentes no entorno dos estudantes". Assim, quando se promove o acesso ao conhecimento científico desde o início da escolarização, proporciona-se a criança, subsídios para que possa constituir e atribuir significados acerca de fenômenos que circundam a própria realidade, desenvolvendo gradativamente os seus conhecimentos e a sua cultura, bem como a possibilidade de compreendê-los (LORENZETTI; DELIZOICOV, 2001). Desse modo, compreende-se que esta área colabora para o desenvolvimento de um posicionamento crítico do sujeito, enfatizando questões que implicam nos aspectos sociais, econômicos, tecnológicos e ambientais que permeiam as múltiplas dimensões da sociedade.

Nesse sentido, compreende-se que a ação docente é crucial para proporcionar ao aluno subsídios para o acesso e mediação do conhecimento científico, principalmente mediante diálogos acerca de temáticas inerentes a Ciências. Para tanto, é necessário que a formação inicial do professor seja permeada por possibilidades de ampliação do repertório de conhecimentos específicos e pedagógicos relativos a determinadas temáticas, extrapolando aspectos que acentuam o grau de dificuldade em desenvolver e sistematizar os conhecimentos específicos atrelados a Ciências (KURZ; BEDIN, 2019). Ademais, espera-se que a formação docente para o ensino de Ciências possa superar a predominância de uma ação pedagógica centrada no docente, pautada na exposição de fenômenos e na descrição de conceitos, reforçando à formação de estudantes passivos frente aos processos de ensino e aprendizagem, desenvolvendo ações com o intuito de fomentar propostas de cunho investigativo, a fim de envolver o estudante na construção de seu conhecimento (NIGRO; AZEVEDO, 2011).

No que tange o contexto descrito, emerge o objetivo do artigo, o qual se atrela aos descompassos do cotidiano escolar e a formação de professores para o ensino de Ciências da 
Natureza nos anos iniciais do Ensino Fundamental. Para tanto, com ênfase nas especificidades e nas implicações das narrativas dos colaboradores desta pesquisa, bem como nas particularidades da ação prática docente no cotidiano escolar, buscou-se analisar, refletir e discutir sobre as possibilidades desencadeadas por estas para a promoção do acesso à cultura científica aos alunos desde o início do processo de escolarização. Deste modo, este artigo tem como pretensão averiguar indícios desta área do conhecimento para a formação e a mobilização de competências, de habilidades e de atitudes no aluno, desde o início do processo de escolarização, por meio da análise das concepções docentes as ações e as possibilidades de acesso do aluno à cultura científica, traçando-se um perfil didático docente entre o dizer e o fazer pedagógico.

Este artigo é importante na medida em que se compreende que a formação docente em Ciências da Natureza deve estar voltada para o desenvolvimento de um sujeito crítico, capaz de compreender e de interpretar o mundo com base em seus conhecimentos científicos, culturais e sociais (BEDIN, 2012). Para tanto, a ação docente tem um papel fundamental neste processo, já que o professor é responsável por propiciar condições, por meio de propostas dinâmicas, colaborativas e integradas, para o acesso e a formalização do conhecimento científico ao sujeito, em consonância com o respectivo nível de ensino (SOBREIRA, 2017). Esta etapa não somente se caracteriza como uma preparação para os demais níveis de ensino, mas como um movimento para capacitar o estudante à interação com a sociedade.

\section{REFERÊNCIAL TEÓRICO}

Discussões acerca dos processos de ensino e aprendizagem na Educação Básica, com ênfase nos anos iniciais do Ensino Fundamental, emergem expressivamente quanto à formação docente, o currículo escolar e o ensino das Ciências da Natureza à luz da alfabetização científica, uma vez que este tripé é chave propulsora para o desenvolvimento da argumentação crítica, para a maximização do raciocínio lógico e para a mobilização de competências, habilidades e atitudes no aluno, o que lhe confere a formação sociocultural para a cidadania. Para tanto, diferentes pesquisas foram e estão sendo desenvolvidas neste viés, tais como os trabalhos de Lorenzetti e Delizoicov (2001), Sasseron (2008), Sobreira (2017), Bedin e Del Pino (2019a) e Kurz e Bedin (2019).

Entende-se que os trabalhos vinculados à formação de professores, buscando promover o acesso e mediação dos conhecimentos científicos, a superação da transmissão de saberes e a fragmentação do ensino, se debruçam, basicamente, em atividades em que o sujeito-aluno é 
visto como um partícipe ativo e autônomo dos processos de ensino e aprendizagem; logo, um membro que não apenas recebe informações, mas as internaliza, as ressignifica e as compartilha com seus pares, tornando-se parte significativa deste meio e da sociedade. Neste aporte, a formação docente adquire espaço "na medida em que o professor percebe a realidade da qual faz/fará parte, projetando uma disposição interna e uma postura de busca permanente de crescimento pessoal e profissional” (BEDIN; DEL PINO, 2019a, p. 71).

Em síntese, espera-se que a processo formação inicial do professor seja pautado na diversificação das práticas pedagógicas, as quais visam o desenvolvimento crítico do discente, assim como lhe propicia subsídios para o acesso à cultura científica, considerando-o como um sujeito ativo do processo de aprendizagem. Afinal, é necessário que o professor seja capaz de entender o significado que tem sobre si e sobre os outros, devendo munir-se de conhecimentos para compartilhar e modificar expressivamente a realidade social da qual é pertencente, preferencialmente desde o início do processo de escolarização. Para tanto, de acordo com Lorenzetti e Delizoicov (2001, p. 13), “o professor precisa tanto desenvolver o espírito crítico e a criatividade, como envolver-se ativamente com a sua comunidade, sendo um formador de opiniões", além de prever-se de competências e de metodologias para desempenhar didaticamente a sua função educativa e alfabetizadora.

Neste aporte, considerando o trabalho do professor em sala de aula, entende-se que o planejamento do currículo escolar é uma das partes integrantes do seu papel como professor, sendo que sua reconstrução ou adaptação, em decorrência de uma dada realidade escolar, pode vincular-se em ações que fundamentam a formação de um sujeito mais ativo e crítico social e culturalmente, possibilitando-lhe o aprofundamento da compreensão científica sobre os fatos e a construção de conhecimentos trabalhados na escola. Isto é, o currículo precisa ser entendido a partir das concepções de Silva (2015, p. 370), quando o pressupõe como uma ação que "ultrapassa a dimensão prescritiva dos textos de propostas que indicam quando muito objetivos, conteúdos e formas". Ou seja, o currículo na Educação Básica é um movimento em que "se expressam também o fazer propriamente dito, as ações por meio das quais se realiza o processo formativo no tempo-espaço da escola" (SILVA, 2015, p. 370).

Todavia, o planejamento do currículo escolar deve estar vinculado a ações que maximizam o papel da escola e dos sujeitos desta com os atores em seu entorno, pois estas estratégias podem, também, organicamente, estarem articuladas com o desenvolvimento e o funcionamento da instituição de ensino; logo, o planejamento docente e o currículo escolar devem estar balizados em especificidades e demandas que se inter-relacionam e se vinculam com os mesmos vieses, dando-se ênfase à formação científica do sujeito. Este desenho é 
importante para que os sujeitos consigam entender a relação que existe entre as diferentes dimensões que abordam o fazer e o dizer pedagógico. Portanto, entende-se que:

Na educação todo cidadão tem uma palavra a dizer... Mas nem tudo o que se diz é pedagogia. A pedagogia opera, em relação aos debates educativos, uma dissociação particular: ela emerge com o reconhecimento da resistência do outro ao próprio projeto educativo, e é isto que constitui, propriamente falando, o momento pedagógico (MEIRIEU, 2002, p. 37).

Neste aporte, à luz de Bedin (2012), compreende-se que o professor deve apresentar uma formação docente, tanto inicial quanto continuada, pautada nas competências, nas habilidades e nas atitudes necessárias para organizar e desenvolver um currículo nutritivo e significativo para o aluno, contemplando elementos que permeiam o cotidiano do sujeito, a fim de instigar-lhe o desenvolvimento de ações e de processos que se vinculam ao ensino de Ciências da Natureza à luz da alfabetização científica. Nesta perspectiva, espera-se que a organização curricular possa corroborar significativamente para a inserção do aluno em seu "processo de aquisição do código escrito, propiciando condições para que os alunos possam ampliar a sua cultura" processo de aquisição do código escrito, propiciando condições para que o mesmo possa ampliar a sua cultura" (LORENZETTI; DELIZOICOV, 2001, p. 48). Nesse linear, a alfabetização científica deve ser entendida como "a capacidade do indivíduo ler, compreender e expressar opinião sobre assuntos que envolvam a Ciência a capacidade do indivíduo ler, compreender e expressar opinião sobre assuntos que envolvam a Ciência" (LORENZETTI; DELIZOICOV, 2001, p. 47) antes mesmo de reconhecer os seus códigos e os seus símbolos (KURZ; BEDIN, 2019; SOBREIRA, 2017).

Assim, de acordo com o supracitado, acredita-se que uma formação docente pautada e solidificada em ações e processos que se vinculam ao ato de ensinar e aprender, considerando o professor como um membro significativo deste processo, e capaz de maximizar a formação do aluno com vistas à alfabetização científica por meio de um currículo estruturado e vinculado ao seu próprio contexto sociocultural, é crucial para a constituição de argumentos críticos, bem como para a intensificação do raciocínio lógico no aluno, na medida em que este se torna parte integrante do processo de aprender. Assim, deve-se considerar que o aluno é um ser com conhecimentos e saberes culturais, os quais devem ser considerados no currículo escolar e nas ações didáticas do professor, a fim de que o sujeito possa se reconstituir na medida em que participa ativamente do processo escolar (BEDIN; DEL PINO, 2019b). 


\section{METODOLOGIA}

Este artigo consiste em um estudo de caso etnográfico, mediante uma perspectiva qualitativa de investigação. Nesse contexto, o estudo de caso realizado no âmbito educacional caracteriza-se como um quadro do paradigma interpretativo, no qual as investigações de caráter qualitativo proporcionam a descrição e a análise holística acerca de um respectivo contexto social singular, no que se refere a um dado acontecimento ou uma sequência de fatos. Ao aderir o estudo de caso com base na etnografia, acrescenta-se uma nova perspectiva a investigação, a de natureza sociocultural (SARMENTO, 2011). Portanto, a adoção dos pressupostos etnográficos em um estudo de caso propicia, além da análise cultural do objeto de pesquisa, uma investigação centrada na perspectiva crítica e interpretativa dos fenômenos simbólicos e culturais que permeiam o dado cotidiano escolar (SARMENTO, 2011).

Desta forma, adotou-se uma abordagem etnográfica, a qual, segundo Cardoso e Costa (2018), caracteriza-se como uma investigação de fenômenos sociais e culturais em que o pesquisador se faz presente no contexto de sua investigação, com o intuito de vivenciar e de compreender as motivações de determinadas ações e comportamentos dos sujeitos envolvidos, bem como realizar uma descrição do respectivo contexto por meio da observação. Nesse linear, a etnografia se distingue dos demais métodos de pesquisa em função de seu enfoque e orientação, uma vez que impõe uma dimensão interpretativa dos símbolos, crenças e valores que compõem a vertente cultural, as quais estão associadas ao objeto de estudo. Para tanto, na Figura 1, encontra-se representados os principais aspectos que norteiam a pesquisa.

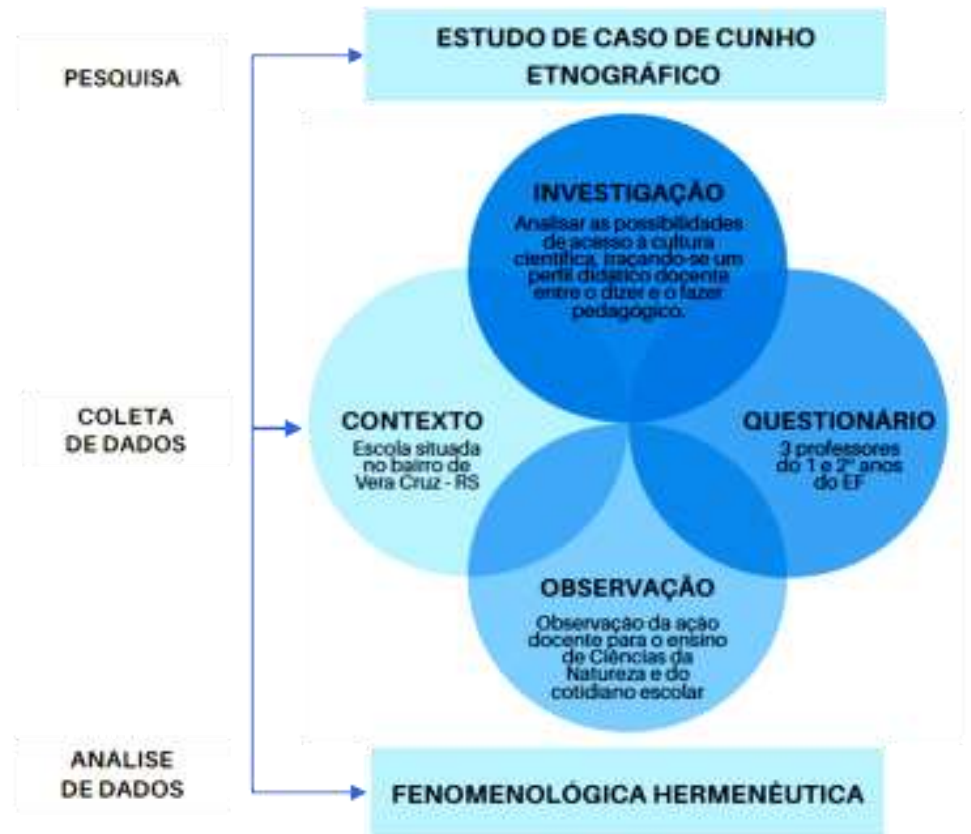

Figura 1 - Esquema dos elementos que norteiam a pesquisa. Fonte: Autores da pesquisa (2020). 
Assim, em conformidade com a Figura 1, tem-se como fonte empírica um questionário respondido por três professoras, bem como as transcrições de um diário de bordo, elaborado a partir da observação do cotidiano escolar, no que tange aspectos atrelados a ação docente, ao ensino de Ciências da Natureza e ao cotidiano escolar das turmas de $1^{\circ}$ e $2^{\circ}$ anos do Ensino Fundamental, de uma escola de Educação Básica situada em um bairro do município de Vera Cruz, no Estado do Rio Grande do Sul. Em relação aos aspectos éticos desta pesquisa, salientase que a mesma foi validada mediante a revisão, a avaliação e a aprovação pelo Comitê de Ética da Universidade Luterana do Brasil, campus Canoas ${ }^{4}$, donde a pesquisa se desencadeia em forma de projeto de mestrado.

Quanto a observação, esta se constitui, na concepção de Ludke e André (1986), como uma das principais estratégias para coletar dados em pesquisas qualitativas, pois a participação direta do pesquisador no lócus da pesquisa lhe possibilita a constatação e a verificação síncrona de dados. Assim, o pesquisador preenche-se de conhecimentos, histórias e experiências pessoais que se complementam na interpretação e na análise do fenômeno em estudo; logo, a observação é uma ferramenta que possibilita ao pesquisador aproximar-se perante diferentes perspectivas de um determinado fato, revelando aspectos que, quiçá, não seriam possíveis de serem compreendidos e relacionados a dadas situações ou outras formas de comunicação (LUDKE; ANDRÉ, 1986). Para tanto, os dados observados pelo pesquisador precisam ser transcritos em momento simultâneo para o diário de bordo, a fim de que o esquecimento ou a reorganização destes não proceda à uma análise desconecta da realidade.

Assim, o diário de bordo foi utilizado como um instrumento de coleta de dados por contemplar relatos de elementos empíricos e reflexivos acerca das vivências e das situações ocorridas no respectivo ambiente escolar, advindos da observação. Além disso, por meio da transcrição dos dados neste instrumento, foi possível pontuar as motivações e os interesses que permeiam a ação docente, sendo possível averiguar as possibilidades de promoção de acesso à informação, atentando à organização do espaço-tempo para a execução das tarefas propostas (WENDLING; CAMPOS, 2013). Não obstante, o diário de bordo se caracteriza como um registro das experiências, o qual propicia a reflexão constante do pesquisador sob o fenômeno em análise, corroborando para a compreensão do caso em estudo, em função dadiversidade e da significância das informações obtidas na investigação.

Para a análise das observações e a transcrições no diário de bordo, adotou-se uma abordagem centrada na proposta fenomenológico-hermenêutica, a qual se caracteriza pela

${ }^{4} \mathrm{O}$ projeto de pesquisa foi aprovado pelo Comitê de Ética em Pesquisa em Seres Humanos sob o $\mathrm{n}^{\mathrm{o}}$ 15115919.9.0000.5349. 
interpretação e pela compreensão do fenômeno em estudo, em conformidade com o respectivo contexto histórico dos acontecimentos; daí a importância da utilização da observação e da transcrição desta para o diário de bordo. Sob esta perspectiva, a transcrição e a interpretação dos dados transcenderam os aspectos de descrição das narrativas dos indivíduos, uma vez que esta proporcionou, tanto aos sujeitos envolvidos quanto ao pesquisador, "um espaço/tempo de escuta e reflexão na/sobre a prática, derivando-se em um processo de construção de conhecimentos e de transformação do contexto do qual faz parte" (BEDIN; DEL PINO, 2018, p. 298), no intuito de averiguar indícios de Ciências da Natureza nos anos iniciais.

Ademais, ressalva-se que os dados apresentados na seção "resultados e discussão" são extensíveis a dada realidade e ao grupo específico de professoras, bem como condizentes ao respectivo espaço-tempo de observação. Deste modo, a análise foi realizada por meio de informações coletadas nas condições mencionadas, as quais podem variar ao longo do ano letivo. Não obstante, entende-se que caso outros contextos fossem contemplados na pesquisa, assim como dispor da participação de outros grupos de professores ou, ainda, considerando outros períodos de observação, possivelmente haveria variações nos achados da pesquisa, e seus desdobramentos no espaço escolar.

\section{RESULTADOS E DISCUSSÃO}

Para compreender as colocações e as concepções das 3 professoras em relação ao desenvolvimento do Ensino de Ciências no início do processo de escolarização, acredita-se ser importante compreender tanto o contexto da escola quanto dos integrantes da mesma, uma vez que estes são elementos que integram o dizer e o fazer pedagógico. Assim, aponta-se a complexidade dos fatores que permeiam o cotidiano escolar dos estudantes, visto que se encontram, em sua maioria, em situação de vulnerabilidade social. Esta questão é específica no Projeto Político Pedagógico da escola, pois em conformidade a este, os sujeitos vivenciam constantes situações de riscos, as quais são decorrentes do uso de entorpecentes, de bebidas alcoólicas, da pobreza e da exclusão social. Ademais, atenta-se à falta de vínculo familiar e casos como de abuso sexual e de violência, bem como a pouca participação e comprometimento dos pais e/ou responsáveis com a aprendizagem dos sujeitos.

Portanto, o somatório destes fatores que colaboram para um significativo índice de reprovação e de evasão escolar, e consequentemente para a falta de perspectivas de muitos alunos para o futuro, no que tange aspectos pessoais e profissionais, reflete no dizer e no fazer pedagógico desta realidade. Sendo assim, é cabível destacar que os dados apresentados abaixo 
são extensíveis a esta realidade e ao grupo de professoras que faz parte da mesma e desta pesquisa, sendo que a análise e a interpretação destes dados são adequadas à observação do pesquisador; logo, quaisquer interpretações das escrituras no diário de bordo, sem a devida observação, podem resultar em diferentes resultados. Assim, a discussão se embasa nas transcrições do diário de bordo, em passagens e excertos das respostas oriundas do questionário e das narrativas das professoras, as quais não se caracterizam somente na análise e na discussão acerca da observação e da conversação com as docentes no decorrer da pesquisa, visto que se pontua as vivências e as concepções das docentes, de modo a estruturar o planejamento pedagógico à luz dos pressupostos da alfabetização científica no ensino de Ciências, transcendendo aspectos decorrentes de leituras que embasam a ação docente.

Nesse sentido, por meio da colaboração das três professoras, das quais duas são professoras responsáveis pelas turmas do $1^{\circ}$ e do $2^{\circ}$ anos do Ensino Fundamental (1PR e 2PR, respectivamente), e a outra (1PE) encontra-se em processo de formação inicial em Pedagogia (Estágio Supervisionado - atuando na turma da 1PR) de uma universidade comunitária, pontuou-se no Quadro $1^{5}$ as concepções destas em relação ao sentir-se preparada para atuar em sala de aula, dando-se ênfase aos conhecimentos específicos e pedagógicos.

\begin{tabular}{|ll|}
\hline Professora 1PR & $\begin{array}{l}\text { Sinto-me preparada para atuar em sala. Acredito que mais pela experiência adquirida, do que } \\
\text { pelo conhecimento específico na graduação. }\end{array}$ \\
\hline Professora 1PE & $\begin{array}{l}\text { Me sinto preparada. Porque estou em constante busca pelo meu aprendizado para me tornar } \\
\text { uma boa educadora. Pois nunca saberemos tudo, aprendemos diariamente. }\end{array}$ \\
\hline Professora 2PR & $\begin{array}{l}\text { Com certeza. Busco proporcionar atividades instigantes para os meus alunos, os desafiando } \\
\text { para sintonizarem-se com a linguagem, utilizando a tecnologia ao meu favor. }\end{array}$ \\
\hline
\end{tabular}
Quadro 1 - Excertos referentes à preparação/planejamento das professoras.

Fonte: Autores da pesquisa (2020).

Com base nos dados do Quadro 1, pode-se perceber que as docentes pontuam sentiremse preparadas para atuar em sala de aula, bem como lidar com as singularidades encontradas nesta; supõe-se a participação de constantes momentos de formação pedagógica. Assim, temse como premissa a ação docente pautada na mediação do conhecimento científico, por meio de uma prática dialógica entre professor e estudante, no qual o processo de construção do conhecimento é permeado pelas vivências e pelos saberes prévios dos sujeitos, de modo a propiciar a inter-relação entre os conteúdos abordados aos elementos que fundamentam o cotidiano dos alunos (VIECHENESKI; LORENZETTI; CARLETTO, 2012).

\footnotetext{
${ }^{5}$ Os excertos dispostos nos Quadros apresentados ao longo do texto são idênticos aqueles apresentados pelas colaboradoras da pesquisa; logo, não se traduziu e não se organizou as escritas das mesmas, a fim de demarcar a essência de suas colocações.
} 
Nessa perspectiva, de acordo com as transcrições do diário de bordo em relação aos excertos das respostas das professoras, e considerando que a ação docente deve fomentar o interesse e o envolvimento dos estudantes nas atividades propostas, a fim de que estes possam ser considerados partícipes do processo de formação, logrando conhecimentos científicos à luz da própria realidade, tem-se uma dicotomia estabelecida entre o dizer e o fazer pedagógico. Isto é, por meio da observação foi possível constatar alguns obstáculos na ação das professoras, os quais não condizem com o que elas ajuízam no questionário. Talvez este processo possa ser derivado da ausência de um planejamento ou pela falta de uma organização hierárquica de assuntos, dificuldades em explorar e discutir determinadas temáticas, bem como ambientes inconvenientes para a realização de determinadas tarefas, como descrito no Quadro 1.1, o qual se contrapõe às colocações do Quadro 1.

\begin{tabular}{|ll|}
\hline Professora 1PR & $\begin{array}{l}\text { Vivenciou-se durante as observações o período de avaliações. Em uma das aulas, solicitou-se a } \\
\text { realização de uma atividade avaliativa, a qual exigia momentos de empenho e concentração dos } \\
\text { alunos. No entanto, não se propiciou rodas de conversas e nem um ambiente favorável para a } \\
\text { realização desta, em função de que parte da turma brincava dentro da sala de aula e a outra parte } \\
\text { realizava as atividades propostas. }\end{array}$ \\
\hline Durante a explicação sobre animais silvestres, a docente somente realizou a leitura do material \\
disponibilizado aos estudantes, não fomentando o envolvimento destes, bem como não \\
propiciou uma discussão pertinente sobre o assunto. Os alunos apresentavam dificuldades de \\
compreender as atividades, visto que sequer conseguiam realizar a identificação de símbolos, \\
sendo que esta solicitou a ordenação dos mesmos.
\end{tabular}

Quadro 1.1 - Indícios da observação em relação a preparação/planejamento.

Fonte: Autores da pesquisa (2020).

Em relação aos Quadros 1 e 1.1, é perceptível que há uma discrepância entre aquilo que as professoras fazem em sala de aula (identificado por meio da observação - Quadro 1.1) e aquilo que elas afirmam fazer (apresentado no questionário - Quadro 1). Ou seja, essa dicotomia estabelecida entre o fazer e o dizer pedagógico é um indício da falta de planejamento ou de uma superficialidade em relação à intencionalidade e a objetivação do mesmo. Assim, compreende-se que a ação de planejar é um momento de reflexão docente que, mediante as singularidades e as especificidades da turma, estrutura a prática pedagógica, corroborando com o aperfeiçoamento das ações educativas e a qualificação dos processos de ensino e aprendizagem, conforme as normativas vigentes (AZAMBUJA et al., 2017).

Ademais, entende-se este momento de planejamento docente como uma ação que propicia subsídios para os processos de ensinar e de aprender, contemplando desde os saberes prévios dos estudantes e os aspectos relativos ao cotidiano destes à diversidade de propostas 
metodológicas para a abordagem de temáticas, como, por exemplo, as "rodas de conversa", as quais se constituem como um espaço privilegiado para o diálogo, pautado na participação efetiva dos sujeitos envolvidos, por meio dos questionamentos, da socialização de ideias, da discussão e das descobertas (CHAER; GUIMARÃES, 2012). Corroborando, Bedin e Del Pino (2019b, p. 136) refletem que as rodas de conversa são importantes porque se caracterizam como mecanismos que potencializam a negociação entre os pares, a qual ocorre na medida em que "um sujeito envolvido auxilia na formação do outro, havendo, além da interação cooperativa e interativa entre os sujeitos, a construção de novas possibilidades que se abrem ao pensar por meio de contínuos movimentos de ação-reflexão-ação".

Portanto, supõe-se que a falta de objetivação das propostas de ensino, quiçá, esteja interconectada com os aspectos decorrentes da própria formação inicial e/ou continuada das professoras, devido ao caráter polivalente da mesma, pois ao mesmo tempo em que pontuam estarem preparadas em termos de conhecimentos específicos e pedagógicos, mediante o respectivo espaço-tempo de observação, pode-se averiguar algumas contradições. Por exemplo, no Quadro 1.1 destaca-se que a professora 1PE somente realizou a leitura de um material, fato que evidencia dificuldades em abordar e sistematizar os conhecimentos atrelados à área de Ciências por diferentes formas. Além disso, de acordo com o Quadro 1, pode-se perceber que a professora 1PR destaca que a sua postura docente é decorrente dos anos de experiência na Educação Básica, e não propriamente dos saberes oriundos do período de formação inicial, detalhando a necessidade de uma postura reflexiva e consciente durante o planejamento e a atuação em sala de aula.

Assim, durante a observação, pode-se perceber que a professora $1 \mathrm{PR}$, por ter anos de experiência, apresentava um planejamento mais sólido e consistente no sentido de envolver o aluno, o que a destacava em relação às demais; logo, tem-se que o professor se constitui na medida em que se aperfeiçoa pela prática docente; é um constructo que se faz caminhando e na prática diária. Destarte, a dispersão entre as colocações das professoras e a observação é pertinente no sentido de entender que "a distância entre o dizer e o fazer só pode ser reduzida mediante uma reconsideração completa do estatuto do pedagógico, do reconhecimento do fundamento ético, da renúncia de toda a certeza didática e da determinação dos professores em colocar a criatividade e a autocrítica no centro da sua conduta" (JESUS, 2010, p. 110).

Não obstante, também se atenta à fragilidade dos cursos de formação inicial de professores, os quais não estão atendendo as demandas impostas pela sociedade, visto que o planejamento da professora 1PE ficou a desejar durante todo o processo de observação, uma vez que, além de não envolver a turma em termos de interação, afetividade e participação nas 
propostas, a professora demonstrava dificuldades em relação a organização de ideias e de conhecimentos. Estes aspectos têm colaborado para as dificuldades de estruturação e de execução de uma ação sistemática atrelada ao ensino de Ciências, fato que está em conformidade com o período observado, visto que tampouco se encontrou indícios de abordagens relacionadas à área de Ciências da Natureza, sendo que quando houve, estes não se pautaram em propostas de cunho investigativo ou similares, somente na exposição de informações memorísticas relativas à Ciências.

Em relação à percepção sobre a turma, de acordo com a Quadro 2, as docentes apontam a imaturidade, a desmotivação e a distração dos estudantes na realização das atividades propostas. No entanto, Pozo (2002) destaca que estes obstáculos tampouco se referem à motivação especificamente, mas aos fatores que a direcionam e a impulsionam, os quais esporadicamente coincidem com os objetivos traçados pelos docentes. Perante esta realidade conflituosa, questiona-se: quais medidas e abordagens didáticas podem ser adotadas para promover o acesso à cultura científica, bem como engajar o estudante na construção do conhecimento científico, mediante sua participação, interesse e curiosidade, no início do processo de escolarização?

\begin{tabular}{|ll|}
\hline Professora 1PR & Imaturos para a turma do $1^{\circ}$ ano. Acredito que seja pela pouca idade. \\
\hline Professora 1PE & $\begin{array}{l}\text { A turma do } 1^{\circ} \text { ano é muito agitada, pouca concentração, muito dispersa. Tive bastante } \\
\text { dificuldade em motivá-los para meu estágio. }\end{array}$ \\
\hline Professora 2PR & $\begin{array}{l}\text { Crianças com um universo de experiências de comunicação concreta e significativas } \\
\text { relacionadas à cultura escrita; aprendem não apenas a ler e escrever, mas se consolidando } \\
\text { com o processo de aprendizagem. }\end{array}$ \\
\hline
\end{tabular}
Quadro 2 - Excertos referentes a percepção da turma. Fonte: Autores da pesquisa (2020).

Ao interpretar os excertos presentes no Quadro 2, percebe-se que, além de haver uma significativa colocação de "imaturidade" nos alunos, há uma discrepância muito expressiva entre as colocações das professoras 1PR e 1PE, mesmo ambas terem atuado na mesma sala de aula, considerando a mesma turma de alunos. Assim, destaca-se, pelas escrituras no diário de bordo, as quais advêm da observação do pesquisador, que realmente há uma série de especificidades na turma, inclusive a concepção de que alguns estudantes necessitam de acompanhamento de profissionais especializados. No entanto, mediante a um planejamento claro, observa-se o envolvimento destes na realização das propostas, bem como o empenho na construção do seu próprio saber, visto que se evidencia uma pré-disposição em "aprender".

Ainda, considerando a questão de imaturidade, é preciso entender que os alunos de $1^{\circ}$ ano do Ensino Fundamental apresentam uma faixa etária entre 6 e 7 anos, e que muitos estão ingressando na escola; um ambiente desconhecido e novo para eles. Os alunos ainda não sabem 
ler e escrever, apresentando baixo raciocínio lógico-matemático, competindo à professora a ação de potencializar estas habilidades e entender os estudantes dentro de suas especificidades. Assim, apesar de a ação didática da professora 1PR ser relevante para a turma, como destacado na discussão do Quadro 1, deve-se entender que "imaturidade" é decorrente de um processo de transição e descobertas, sendo necessário contemplar as particularidades dessa fase de escolarização, no que tange subsídios para corroborar com o processo de inserção deste estudante nesta etapa escolar, primando por atividades de caráter lúdico e considerando elementos que permeiam o cotidiano do discente (BRASIL, 2017).

Quando questionadas em relação às metas e às expectativas em termos de competências e habilidades a serem desenvolvidas para cada turma, as docentes responderam com perspectivas futuras significativas à formação dos sujeitos, como se expõe no Quadro 3.

\begin{tabular}{|ll|}
\hline Professora 1PR & Dar conta das competências e habilidades apresentadas na BNCC. \\
\hline Professora 1PE & $\begin{array}{l}\text { No período de estágio, eram conhecerem os animais, as suas características, através deles } \\
\text { aprenderem a escrever, ler e efetuar operações matemáticas. Também regras básicas de } \\
\text { respeito e cuidados. }\end{array}$ \\
\hline Professora 2PR & $\begin{array}{l}\text { Que o aluno seja capaz de, pelo menos, participar em situações de exposição oral, planejando } \\
\text { sua fala adequadamente; ler diferentes gêneros textuais; escrever considerando produção } \\
\text { textual de sua própria autoria. }\end{array}$ \\
\hline
\end{tabular}

Quadro 3 - Excertos referentes a metas e expectativas em termos de competências.

Fonte: Autores da pesquisa (2020).

Considerando as colocações no Quadro 3, percebe-se que as professoras pontuam em termos de competências e de habilidades a formação de um sujeito ativo, autônomo e crítico com o meio, uma vez que contemplam ações de leitura, escrita e fala. Todavia, a partir das observações, pode-se constatar que apenas a professora 2PR proporcionava abertura ao debate e potencializava os alunos à mobilização das competências descritas, uma vez que propiciava a estes momentos de escrita e de leitura dos próprios textos, instigando-os a socialização de ideias e a valorização da interação entre os pares. Em relação às professoras 1PR e 1PE, com ênfase na professora 1PR, pode-se afirmar que as ações didáticas desta, apesar de instigarem a mobilização dos alunos em sala de aula, não se caracterizavam como efetivas no sentido de atingir as competências e as habilidades presentes na BNCC, como a mesma descreve.

Afinal, a ação da professora 1PR, em relação ao movimento necessário para desenvolver as competências e as habilidades na BNCC, foi insuficiente em múltiplas situações, tais como no sentido de aguçar o pensamento científico, crítico e criativo; potencializar o autoconhecimento e o autocuidado; e, dentre outras, favorecer a inserção da cultural digital. Isto se solidifica ainda mais quando à professora foi possibilitado demonstrar como suas ações estão vinculadas às competências e às habilidades da BNCC, sugerindo-a, no questionário, 
justificar sua resposta, o que não ocorreu; logo, ao não se identificar os objetivos docentes traçados, supôs-se a não apropriação de aspectos objetivados pela mesma.

Assim, evidencia uma distância significativa entre o que as professoras expõem e o que elas, realmente, desenvolvem na prática pedagógica. É neste sentido que Meirieu (2002, p. 125) coloca que a "pedagogia constitui-se então como atividade em tensão permanente entre o que escraviza e o que alforria, atividade geralmente medíocre, sempre frágil, mas na qual, às vezes se pode resgatar um pouco de humanidade". O autor, ainda, esclarece que "é a própria contradição do discurso pedagógico que o torna não apenas tolerável, mas, a nosso ver, absolutamente insubstituível” (MEIRIEU, 2002, p. 125). Neste viés, verifica-se, tanto nas colocações das professoras quanto na observação realizada, que o ensino de Ciências permeia como um momento coadjuvante dos processos de ensino e aprendizagem, dando-se ênfase, primordial, nos conteúdos vinculados a área de Matemática e as linguagens verbal e escrita (VIECHENESKI; LORENZETTI; CARLETTO; 2012; ROSA et al., 2007).

Nesse sentido, averiguou-se uma ênfase ao ensino de Língua Portuguesa, como o estudo de letras do alfabeto, diferentes gêneros textuais e a produção textual, assim como se identificou a necessidade de enfatizar os assuntos atrelados ao ensino da Matemática, no que se refere à cálculos relativos às quatro operações e à resolução de problemas. Ademais, quando emergiu indícios relativos a Ciências da Natureza no planejamento docente, constatou-se que a presença desta era em detrimento das demais áreas do conhecimento. Logo, do mesmo modo que se averiguou a insegurança docente frente ao desenvolvimento de tais temáticas, visto que durante a explicação não se observou o detalhamento e a discussão sobre dado tema, apenas realizouse uma breve leitura do material disponibilizado aos alunos.

Nesta linha, Sobreira (2017), com base nas pesquisas de Nigro e Azevedo (2011), salienta que tal situação ocorre em detrimento dos esforços destinados ao letramento dos estudantes nos anos iniciais, mas não justifica a ausência da maximização das outras Ciências, essencialmente àquelas que potencializam a argumentação crítica e o desenvolvimento do raciocínio lógico. A partir das análises realizadas no Quadro 4, evidencia-se um consenso em relação à importância do ensino de Ciências nos anos iniciais do Ensino Fundamental, tanto por se tratar de um direito de todos quanto pela importância de os alunos compreenderem os fenômenos presentes no próprio cotidiano. 


\begin{tabular}{|ll|}
\hline Professora 1PR & Pela importância que a Ciências tem na vida de todos. \\
\hline Professora 1PE & $\begin{array}{l}\text { É importante ensinar Ciências de maneira a instigar os sujeitos a querer aprender mais. Ela } \\
\text { começa a ensinar o próprio corpo, os seres vivos, o mundo que nos rodeia. Ensinando assim } \\
\text { a respeitar, cuidar de si, do meio... }\end{array}$ \\
\hline Professora 2PR & $\begin{array}{l}\text { Porque as crianças têm o direito de aprender Ciências. Para que o aluno se torne sujeito de sua } \\
\text { aprendizagem, para refletir, contextualizar saberes de casa, da rua e do grupo social, } \\
\text { relacionando-os com o ambiente escolar. }\end{array}$ \\
\hline
\end{tabular}

Quadro 4 - Excertos referentes à importância do ensino de Ciências nos anos iniciais.

Fonte: Autores da pesquisa (2020).

Não diferente das ações até aqui descritas, em relação às observações e as transcrições para o diário de bordo, aqui também se observa um distanciamento gritante entre àquilo que as professoras apontam em respostas a questão e àquilo que, efetivamente, elas realizam em sala de aula, para buscar a promoção do ensino de Ciências no início do processo de escolarização. Isto é, as professoras afirmam que ensinar Ciências nos $1^{\circ}$ e $2^{\circ}$ anos do Ensino Fundamental é importante para que o sujeito seja instigado a aprender, entender o próprio corpo e o mundo que o rodeia, ressignificando os saberes advindos de casa a partir do conhecimento construído coletivamente em sala de aula. Todavia, as ações didáticas desenvolvidas não mobilizam tais habilidades, uma vez que as professoras enfatizam a leitura e a escrita como princípios primordiais da alfabetização. Assim, entende-se que a "pedagogia não funciona como prescrição, como decreto, como algo linear" (FRANCO, 2011, p. 210). Isto é "ela precisa estar sendo gestada e construída a cada momento pedagógico. Tirar do docente a possibilidade de agir no momento pedagógico, com ousadia e competência, é tirar dele as possibilidades pedagógicas" (FRANCO, 2011, p. 210).

A critério de curiosidade, fez-se o Quadro 5 que apresenta em síntese a ideia geral das ações docentes em sala, a fim de entender a relação entre o dizer e o fazer pedagogicamente.

\begin{tabular}{|ll|}
\hline Professora 1PR & $\begin{array}{l}\text { A ação docente da responsável contemplava uma diversificação de atividades realizadas, como } \\
\text { dobraduras, pinturas, cantigas, bem como propiciava o envolvimento dos estudantes. No } \\
\text { entanto, as atividades observadas remetiam a assuntos de Língua Portuguesa e Matemática. }\end{array}$ \\
\hline Professora 1PE & $\begin{array}{l}\text { Durante o Estágio Curricular Supervisionado, observou-se uma série de dificuldades no que } \\
\text { tange a ação docente, visto que tampouco conseguiu propiciar o envolvimento dos estudantes } \\
\text { durante as explicações e na realização de tarefas, os quais se encontravam dispersos. }\end{array}$ \\
\hline Professora 2PR & $\begin{array}{l}\text { A ação docente pauta-se em recompensas pela realização das atividades com empenho. Apesar } \\
\text { de promover a realização de algumas atividades lúdicas, são ações muito pontuais. Do mesmo } \\
\text { modo, apresenta dificuldade na explicação de alguns temas sob diferentes perspectivas. }\end{array}$ \\
\hline
\end{tabular}

Quadro 5 - Síntese geral da ação docente em sala de aula.

Fonte: Autores da pesquisa (2020).

Nesse sentido, conforme supracitado, pontua-se sobre o consenso em relação à importância do ensino de Ciências, o qual está presente nos discursos das professoras, mas não efetivado na ação pedagógica destas, em detrimento das demais disciplinas. Por exemplo, observou-se na aula de Educação Física que a professora, no início do ano letivo, em função 
tanto da realização das atividades físicas quanto das temperaturas elevadas, solicitou que os estudantes trouxessem água para beber. No entanto, ao observar que os alunos trouxeram refrigerantes e sucos artificiais, a professora abordou a temática para o desenvolvimento de uma pesquisa em relação às implicações causadas pelo consumo excessivos destas bebidas, além de pontuar a quantidade de açúcares presentes nas mesmas, destacando a importância do consumo de água para o corpo humano. Logo, é importante que alguns aspectos transcendam o discurso, de modo que se possa evidenciar estes na ação docente, para pensar sobre a discrepância entre os projetos educativo e de vida e as decisões tomadas (MEIRIEU, 2002).

Ademais, atenta-se que nesta etapa de ensino deve-se promover o acesso a diversidade do conhecimento científico, com o intuito de propiciar o primeiro contato com assuntos relativos a Ciências não especificamente às questões voltadas ao ensino de Biologia, mas as manifestações dos fenômenos naturais. Este deve ocorrer de formas gradativa e processual, por meio de propostas que possibilitam aos estudantes vivenciarem os processos de investigação, observação, análise, discussão e socialização das ideias. Ainda, e tampouco, cabe ao professor não se deter com a precisão e a sistematização rigorosa de conceitos, visto que este movimento consiste em um processo constante de construção e de reconstrução dos significados atribuídos a um determinado fenômeno.

Outra indagação realizada às professoras estava vinculada à prática efetiva do ensino de Ciências durante o processo de formação do aluno, ou seja, questionou-se: Você desenvolve ou já desenvolveu aulas de Ciências em suas turmas? Por quê? As colocações das professoras, sem alternância, estão presentes no Quadro 6.

\begin{tabular}{|cl|}
\hline Professora 1PR & $\begin{array}{l}\text { Sim. Pela importância de os alunos entrarem em contato com os conteúdos de Ciências: corpo } \\
\text { humano, animais. }\end{array}$ \\
\hline Professora 1PE & $\begin{array}{l}\text { Sim. Para que os alunos tivessem consciência que adotar animais requer responsabilidades, } \\
\text { cuidados, respeito e amor. }\end{array}$ \\
\hline Professora 2PR & $\begin{array}{l}\text { Higiene pessoal. Para adquirirem noções fundamentais de cuidarem de si e os conscientizarem } \\
\text { da importância da higiene corporal. Coleta seletiva do lixo. Promover a conscientização } \\
\text { ambiental. Seres vivos e não vivos. Reconhecê-los e compreender determinados ambientes. }\end{array}$ \\
\hline Quadro 6 - Excertos referentes ao desenvolvimento efetivo do ensino de Ciências. \\
Fonte: Autores da pesquisa (2020).
\end{tabular}

Com ênfase nas colocações das professoras em respostas ao questionamento e, em conformidade com as pesquisas na área (KURZ; BEDIN, 2019; ROSA et al., 2007), assim como com as escrituras transcritas no diário de bordo a partir das observações, evidencia-se a atribuição do ensino de Ciências aos conhecimentos relativos à Biologia, seja aos aspectos atrelados a higiene pessoal, ao corpo humano ou a fauna e flora, os quais são considerados como saberes norteadores desta área do conhecimento. 
Ademais, a partir das colocações, é percebível que as professoras trabalham questões relativas ao corpo humano e a higienização, justificando o trabalho pela localização da escola e o público-alvo pertencente à mesma. Ou seja, as professoras desenvolvem questões científicas com os alunos dentro da sala de aula, instigando-os a pensarem cientificamente, mas não fortalecem a análise e a interpretação do desenvolvimento de fenômenos naturais e artificiais, priorizando o ensino de Ciências da Natureza como um todo. Este desenho é importante porque se acredita que quando o ensino desta área é desenvolvido em diferentes vieses e solidificado nas três disciplinas que compõem a área (Química, Física e Biologia), a compreensão do sujeito em relação à Ciências do seu cotidiano pode abrir-lhe portas para a formação cidadã, mobilizando, quiçá, as competências e as habilidades destacadas na BNCC.

Quanto às possibilidades para explorar as temáticas relativas ao ensino de Ciências, as docentes pontuam a importância das atividades experimentais, entretanto durante o período de observação não foi contemplando o uso desta. Quanto aos indicadores que influenciam esta decisão, apontam a falta de espaço e a ausência de material para a realização de atividades experimentais, visto que conforme identificado no PPP, o laboratório de Ciências, o qual tem por finalidade auxiliar na construção de conceitos científicos, dentro de uma proposta pedagógica que alia reflexão e ação, atualmente abriga uma classe regular, devido à infraestrutura da escola. Portanto, sua utilização restringe-se ao uso de alguns materiais, em função das demandas da escola, o que não justifica a ausência do ensino de Ciências em sala de aula ou o desenvolvimento deste com vistas ao ensino de Biologia.

\section{CONSIDERAÇÕES}

Diante do exposto e a partir das transcrições do diário de bordo, das narrativas dos colaboradores da pesquisa e dos excertos oriundos do questionário, evidencia-se a fragilidade do acesso a diversidade de conhecimentos científicos e à cultura científica, no que tange o ensino de Ciências da Natureza nos anos iniciais do Ensino Fundamental, no respectivo contexto escolar, visto que o mesmo é permeado pela vulnerabilidade social dos sujeitos que integram a comunidade escolar, assim como em decorrência da ação docente que pouco propicia subsídios para o desenvolvimento de assuntos relativos a Ciências.

De modo geral, supõe-se que estas limitações estejam atreladas a especificidades da formação inicial e continuada de professores, como já pontuado em outras pesquisas (LORENZETTI; DELIZOICOV, 2011; SOBREIRA, 2017; KURZ; BEDIN, 2019). Afinal, embora as professoras contemplem em suas práticas pedagógicas as vivências, os saberes 
prévios dos estudantes e os elementos que permeiam o cotidiano destes, bem como algumas propostas que fomentam o envolvimento e a participação dos sujeitos nas atividades, direcionam suas atividades, em sua maioria, somente as áreas de Língua Portuguesa e Matemática, envolvendo o ensino de Ciências, quando o fazem, com ênfase na Biologia, como coadjuvante do processo de construção de saberes.

Não obstante, também se supõe que a concepção docente em relação ao ensino de Ciências da Natureza está diretamente relacionada ao entendimento desta área do conhecimento, por meio de saberes atrelados somente ao ensino de Biologia, como pode ser observado nas respostas, as quais destacaram estudo sobre a fauna e flora e a higiene pessoal. No entanto, ao se referir a este componente curricular, averiguou-se, por meio da observação, a predominância de uma didática pautada na transmissão e na memorização dos conceitos científicos; talvez em função da singela apropriação do conhecimento científico aliado a insegurança na abordagem desta temática, fato que corroborou com a restrição do saber científico aos discentes, bem como se configura como um obstáculo para a atribuição de sentidos e significados aos objetos em estudo (LORENZETTI; DELIZOICOV, 2001).

Ainda, é importante reafirmar a dicotomia estabelecida entre o que as professoras dizem fazer em sala de aula, como respostas ao questionário, com aquilo que efetivamente elas realizam, em relação a observação. Isto é, com a pesquisa, mesmo que implicitamente, evidenciou-se a falta de "coerência" e de planejamento das professoras em relação à efetiva prática didática. Este desenho é um indício de ponderação para que se possa pensar e refletir sobre a identidade docente, a qual pode se perder na representatividade do discurso e na singularidade da ação. Logo, é necessário e imprescindível que estas professoras comecem a repensar o discurso que realizam sobre o seu próprio fazer pedagógico nos anos iniciais, bem como refletir e aperfeiçoar as práticas pedagógicas que desenvolvem neste contexto, principalmente por meio da participação de momentos de formação continuada voltados a reflexão sobre a prática docente, visando minimizar e demover os problemas, corroborando com mudanças significativas no espaço escolar (BLASZKO, 2014).

Destarte, destaca-se que a partir desta pesquisa serão elencadas algumas propostas pedagógicas e estratégias didáticas para, a partir de competências, habilidades e atitudes docentes, estruturar ações potencialmente significativas que vinculam o dizer e o fazer pedagógico destas professoras, enfatizando-se os processos de ensino e aprendizagem à luz da alfabetização científica no que tange o ensino de Ciências da Natureza nos anos iniciais do Ensino Fundamental. Afinal, o ensino de Ciências deve ser desenvolvido em um viés de formação crítica e cidadã desde o início do processo de escolarização, buscando validar, para 
além da ressignificação dos saberes culturais à luz do conhecimento científico, a vivência, o contexto e a cultura dos alunos, da escola e do seu entorno.

\section{AGRADECIMENTOS}

Os autores agradecem a Coordenação de Aperfeiçoamento de Pessoal de Nível Superior (CAPES) pelo suporte à esta pesquisa.

\section{REFERÊNCIAS}

AZAMBUJA, P. L.; CONTE, E.; HABOWSKI, A. C. O planejamento docente na educação infantil: metamorfoses e sentidos ao aprender. Pesquisa e Foco, v. 22, n. 2, 2017, p. 157-178. Disponível em: https://doi.org/10.18817/pef.v22i2.1503. Acesso em: 29 ago. 2020.

BEDIN, E. Formação de professores de química: um olhar sobre o Pibid da Universidade Federal de Uberlândia. 2012. 166 f. Dissertação (Mestrado) - Universidade Federal de Uberlândia, Programa de Pós-Graduação em Química, Uberlândia, 2012.

BEDIN, E.; DEL PINO, J. C. A formação inicial de professores de química a partir da integração e da cooperação nas rodas de conversa: um caso específico. Revista Debates em Ensino de Química, v. 4, n. 2, 2019a, p. 68-85. Disponível em: http://journals.ufrpe.br/index.php/REDEQUIM/article/view/2011. Acesso em: 29 ago. 2020.

BEDIN, E.; DEL PINO, J. C. Análise de Atitudes: proposições docentes sobre a utilização de Rodas de Conversa na formação inicial de professores. Revista de Estudos e Pesquisas sobre Ensino Tecnológico (EDUCITEC), v. 5, n. 11, 2019b, p. 132-149. Disponível em: https://doi.org/10.31417/educitec.v5i11.730. Acesso em: 29 ago. 2020.

BEDIN, E.; DEL PINO, J. C. Situação de Estudo como artefato para a qualificação metodológica. Educar em Revista, v. 34, n. 69, 2018, p. 293-309. Disponível em: https://revistas.ufpr.br/educar/article/view/53297. Acesso em: 29 ago. 2020.

BRASIL. Base Nacional Comum Curricular (BNCC). Educação é a Base. Brasília, 2017. Disponível em: http://basenacionalcomum.mec.gov.br/. Acesso em: 14 out. 2020.

BLASZKO, C. E. O uso do blog aliado ao ensino de ciências para a formação dos professores dos anos iniciais do ensino fundamental. 2014. 118 f. Dissertação (Mestrado) Universidade Tecnológica Federal do Paraná, Programa de Pós-Graduação em Ensino de Ciências e Tecnologia, Ponta Grossa, 2014.

CARDOSO, L. C. M.; COSTA, M. L. Notas sobre a prática de pesquisa etnográfica no campo da Comunicação. Questões Transversais, v. 5, n. 10, p. 1-8 2018. Disponível em: http://revistas.unisinos.br/index.php/questoes/article/view/15734. Acesso em: 15 out 2020.

CHAER, M. R.; GUIMARÃES, E. G. A. importância da oralidade: educação infantil e séries iniciais do Ensino Fundamental. Pergaminho-Centro Universitário de Patos de Minas, v. 3, n. 1, p. 71-88, 2012.

FRANCO, M. A. S. Philippe Meirieu: fragmentos de uma Conversa. Revista Eletrônica 
Pesquiseduca, v. 3, n. 6, p. 274-281, 2011. Disponível em:

http://periodicos.unisantos.br/index.php/pesquiseduca/article/viewFile/192/pdf. Acesso em: 25 ago. 2020.

JESUS, A. M. P. Contributos de Philippe Meirieu para uma pedagogia inovadora: "da pedagogia magistral à pedagogia diferenciada". 2010. 300 f. Tese (Doutorado) - Universidade da Madeira, Programa de Ciências da Educação, Funchal, 2010.

KURZ, D. L.; BEDIN, E. As possibilidades de um e-book de experimentos para a promoção da alfabetização científica na área de ciências da natureza nos anos iniciais do ensino fundamental. Redin-Revista Educacional Interdisciplinar, v. 8, n. 1, 2019. Disponível em: http://seer.faccat.br/index.php/redin/article/view/1439. Acesso em: 15 ago. 2020.

LORENZETTI, L.; DELIZOICOV, D. Alfabetização científica no contexto das séries iniciais. Ensaio Pesquisa em educação em Ciências, v. 3, n. 1, p. 45-61, 2001. Disponível em: https://doi.org/10.1590/1983-21172001030104. Acesso em: 30 ago. 2020.

LUDKE, M.; ANDRÉ, M. E. D. A. Pesquisa em educação: abordagens qualitativas. São Paulo, Editora Pedagógica e Universitária, 1986.

MEIRIEU, P. A pedagogia entre o dizer e o fazer: a coragem de começar. Artmed, 2002.

NIGRO, R. G.; AZEVEDO, M. N. Ensino de ciências no fundamental I: perfil de um grupo de professores em formação continuada num contexto de alfabetização científica. Ciência \& Educação, v. 17, n. 3, p. 705-720, 2011. Disponível em: 10.1590/S151673132011000300012. Acesso em: 25 ago. 2020.

POZO, J. I. La adquisición del conocimiento científico como un proceso de cambio representacional. Investigações em ensino de ciências, vol. 7, n. 3, p. 245-270, 2002. Disponível em: http://hdl.handle.net/10486/666207. Acesso em: 25 ago. 2020.

ROSA, C. W.; PEREZ, C. A. S.; DRUM, C. Ensino de física nas séries iniciais: concepções da prática docente. Investigações em Ensino de Ciências, v. 12, n. 3, 2007. Disponível em: https://www.if.ufrgs.br/cref/ojs/index.php/ienci/article/view/465. Acesso em: 29 ago. 2020.

SARMENTO, M. J. O estudo de caso etnográfico em educação. 2011.

SASSERON, L. H. Alfabetização científica no ensino fundamental: estrutura e indicadores deste processo em sala de aula. 2008. $281 \mathrm{f}$. Tese (Doutorado) - Universidade de São Paulo, Programa de Pós-Graduação em Educação, São Paulo, 2008.

SILVA, M. R. Currículo, ensino médio e BNCC-Um cenário de disputas. Retratos da Escola, v. 9, n. 17, 2015. Disponível em: file:///C:/Users/Acer/Downloads/586-1898-1-PB.pdf. Acesso em: 30 ago. 2020.

SOBREIRA, E. S. R. Tecnologias digitais no ensino de ciências para crianças: autoria e interações em uma proposta educativa explorando o tema energia. 2017. $263 \mathrm{f}$.

Dissertação (Mestrado) - Universidade Estadual de Campinas, Programa de Pós-Graduação em Multiunidades em Ensino de Ciências e Matemática, Campinas, 2017. 
VIECHENESKI, J. P.; LORENZETTI, L.; CARLETTO, M. R. Desafios e práticas para o ensino de ciências e alfabetização científica nos anos iniciais do ensino fundamental. Atos de Pesquisa em Educação, v. 7, n. 3, p. 853-876, 2012. Disponível em:

http://dx.doi.org/10.7867/1809-0354.2012v7n3p853-876. Acesso: 31 ago. 2020.

WENDLING, C. M.; CAMPOS, S. D. Análise dos registros em diário de bordo sobre alfabetização. São Paulo: Presidente Prudente, 2013.

Submetido em: 07 de setembro de 2020 .

Aprovado em: 26 de outubro de 2020. 